\title{
Duodenal Gastrin-Producing Neuroendocrine Tumor
}

National Cancer Institute

\section{Source}

National Cancer Institute. Duodenal Gastrin-Producing Neuroendocrine Tumor. NCl

Thesaurus. Code C5731.

A gastrin-producing neuroendocrine tumor that arises from the duodenum. It is characterized by the presence of uniform cells that form pseudorosettes. The neoplastic cells have uniform nuclei and small amount of eosinophilic cytoplasm. 